\title{
ZERO-CROSSING DERIVATIVE SPECTROPHOTOMETRY AND LIQUID CHROMATOGRAPHIC METHOD FOR THE QUANTITATIVE DETERMINATION OF CLOPIDOGREL IN PRESENCE OF HMG CO-A REDUCTASE INHIBITORS
}

\author{
NAJMA SULTANA ${ }^{1}$ MUHAMMAD SAEED ARAYNE ${ }^{2}$, MUHAMMAD NAWAZ $^{3 *}$ AND KIRAN AMIR ALI \\ ${ }^{1}$ Research Institute of Pharmaceutical Sciences, Department of Pharmaceutical Chemistry, Faculty of Pharmacy, \\ University of Karachi, Karachi-75270. Pakistan. \\ ${ }^{2}$ Department of Chemistry, University of Karachi; Karachi-75270. Pakistan. \\ ${ }^{3}$ Department of Chemistry, United Arab Emirates University, Al-Ain-17551,UAE
}

(Received: July 11, 2011 - Accepted: October 18, 2012)

\begin{abstract}
In this work, two methods are described for the simultaneous determination of clopidogrel bisulfate with HMG Co-A reductase inhibitors/statins. The first method comprised of quantitative determinations of clopidogrel bisulfate in presence of HMG Co-A reductase inhibitors (atorvastatin, pravastatin simvastatin and rosuvastatin) in buffers of $\mathrm{pH} \mathrm{1,} 4$ (simulating gastric environments), $\mathrm{pH} 7.4$ (simulating blood $\mathrm{pH}$ ) and $\mathrm{pH} 9$ (simulating intestinal $\mathrm{pH}$ ) at body temperature $\left(37^{\circ} \mathrm{C}\right)$ using UV/VIS spectrophotometer. Derivative spectroscopy coupled with zero-crossing measurements was used for separating the interfering wavelengths of clopidogrel and statins. Least square regression analysis was performed to measure the concentrations of these drugs. It was observed that clopidogrel interacted with statins at all four $\mathrm{pH}$, especially in simulated gastric environments. In the second case, reversed phase liquid chromatographic (RP-LC) method was developed for simultaneous determination and to investigate the interactions between clopidogrel and HMG Co-A reductase inhibitors. These interactions were evaluated by RP-LC in buffers of $\mathrm{pH} 1,4,7.4$ and 9 . These studies further supported the evidence of complexation between clopidogrel and statins as the area under the curve (AUC) was found increased in almost all four $\mathrm{pH}$ solutions.
\end{abstract}

Key words: Clopidogrel, Statins, Interactions, UV-Vis, RP-HPLC

\section{INTRODUCTION}

Clopidogrel is a potent antiplatelet drug, indicated for the prevention of vascular thrombotic events in patients at risk ${ }^{1}$. It has an absolute $S$ configuration at carbon 7; the corresponding $R$ enantiomer is totally devoid of antiaggregating activity, thus indicating the importance of configuration of this asymmetric carbon for the biological activity. ${ }^{2}$ Statins (HMG Co-A reductase inhibitors), the most effective among the principal groups of hypolipidemic agents, specifically inhibit HMG-CoA reductase by competition, the enzyme that catalyzes the conversion of HMG-CoA to mevolanate, which is an early rate-limiting step in cholesterol biosynthesis in the body ${ }^{3}$. They are highly effective in reducing total cholesterol and the LDL levels in several forms of hypercholesterolemia ${ }^{4-8}$. Clopidogrel is an inactive prodrug, which requires activation by the cytochrome P450 3A4 system in order to exert its antiplatelet action. Some statins (atorvastatin, lovastatin and simvastatin) also requires metabolism by the cytochrome P450 3A4 system. From a theoretical point of view, a clinical relevant interaction may exist between clopidogrel and cytochrome P450 3A4 metabolized statins. Several studies have debated the existence/absence of this potential interaction ${ }^{9-12}$. Derivative spectrophotometry, based on a mathematical transformation of the spectral zero order curves into the derivative spectra, allows a fast, sensitive and precise resolution of a multicomponent mixture ${ }^{13}, 14$. It is coupled with zero-crossing measurements, involves measurement of the absolute value of the total derivative spectrum at an abscissa value corresponding to the zero-crossing wavelength of the derivative spectra of individual components which should be only a function of the concentration of other component.

In view of the potential interactions, which may ultimately be hazardous, the present study is aimed to study drug interactions of clopidogrel with commonly prescribed HMG Co-A reductase inhibitors, like atorvastatin, simvastatin, pravastatin and rosuvastatin, in vitro, in buffers of $\mathrm{pH} 1,4,7.4$ and 9 at body temperature $\left(37^{\circ} \mathrm{C}\right)$.

\section{EXPERIMENTAL}

\section{Materials and reagents}

Authentic samples of clopidogrel bisulphate was kindly supplied by Getz Pharma (Pvt.) Ltd. Pharmaceutical grade atorvastatin, simvastatin, pravastatin and rosuvastatin were provided by Pacific Pharmaceuticals Ltd., Platinum Pharmaceuticals (Pvt) Ltd., Bristol-Meyers Squibb Pakistan (Pvt.) Ltd. and Pharm Evo (Pvt.) Ltd. respectively. Commercial pharmaceutical preparations were purchased from the local market. All reagents used were of analytical grade. Methanol, acetonitrile (Tedia, USA) and deionized water were used for the preparation of mobile phase.

\section{Instrumentation}

- Dissolution test apparatus (B.P. 2007)

- Shimadzu 1601 double beam spectrophotometer with a fixed slit width (2 $\mathrm{nm}$ ) connected to a computer loaded with Shimadzu UVPC Software used for all the absorbance measurements and treatment of data.

- Shimadzu HPLC system (LC 10AT-VP) consisting of a Rheodyne injector (20-uL), UV detector (SPD 10A-VP) and Class-GC 10 software (Shimadzu, Kyoto, Japan) for data acquiring and calculation of system suitability parameters. The analytical column used to achieve chromatographic separation was Purospher start C18 $(5 \mu \mathrm{m}, 250 \times 4.6 \mathrm{~mm})$.

\section{Interactions studies using UV-Vis sectrophotometry}

Buffers of $\mathrm{pH} \mathrm{1,} \mathrm{4,} 7.4$ and 9 were used to prepare standard solution of both clopidogrel and statins. The concentration range for clopidogrel was $3218-17700 \mu \mathrm{gmL}^{-1}$. Similarly working standard solutions of statins ranging from $2793-30725 \mu \mathrm{gmL}^{-1}$ for atorvastatin, $4245-42453 \mu \mathrm{gmL}^{-1}$ for pravastatin, 4815-26485 $\mathrm{ggmL}^{-1}$ for rosuvastatin were prepared. In case of simvastatin, the range was $5023-12557 \mu_{\mathrm{gmL}^{-1}}$ in simulated gastric juice and $6278-20929$ $\mu \mathrm{gmL}^{-1}$ in buffers of $\mathrm{pH} 4,7.4$ and 9 .

All the zero order spectra recorded were transformed into their respective derivative order. The calibration curves obtained (absorbance versus concentration) obeyed Beer Lambert's law was at all concentrations.

\section{In vitro availabilities}

The in vitro availabilities of clopidogrel and interacting drugs were investigated in absence as well as in presence of each other in all four different buffers under study on a modified B.P 2007 dissolution apparatus. In first set of experiments, dissolution test was run alone for clopidogrel and interacting drugs while to investigate the interaction in presence of the competitor, clopidogrel tablet was added to the dissolution medium at zero time while the interacting drug was added after 15 minutes interval in dissolution medium maintained at specified temperature $\left(37^{\circ} \mathrm{C}\right)$. Aliquots of $5 \mathrm{~mL}$ samples were drawn periodically at 15 minutes time intervals for 120 minutes. The drug contents were determined spectrophotometrically at their respective $\lambda_{\max }$ using the dissolution medium as blank. Concentration $(\log )$ versus time graphs were plotted to study the effect of statins on availability of clopidogrel.

Interactions studies using high performance liquid chromatography

Chromatographic estimations were performed using Purospher start C18 column $(5 \mu \mathrm{m}, 250 \times 4.6 \mathrm{~mm}$, ) with mobile phases comprising methanol : water $(80: 20 \mathrm{v} / \mathrm{v})(\mathrm{pH} 3.4)$ for atorvastatin and pravastatin, acetonitrile : methanol : water $(60: 30: 10 \mathrm{v} / \mathrm{v} / \mathrm{v})(\mathrm{pH} 3.4)$ for simvastatin and methanol : water $(65: 35$ $\mathrm{v} / \mathrm{v})(\mathrm{pH} 3.2)$ for rosuvastatin. These mobile phases were degassed, filtered through a $0.45 \mu \mathrm{m}$ filter and all pumped at a flow rate of $1 \mathrm{~mL} \mathrm{~min}{ }^{-1}$ but rosuvastatin at $1.2 \mathrm{~mL} \mathrm{~min}^{-1}$ using isocratic pump system. The elutents were 
monitored at $240 \mathrm{~nm}$, keeping an injection volume of $20 \mu \mathrm{L}$.

Working standards were prepared by diluting the stocks solutions of clopidogrel and statins $\left(100 \mu \mathrm{gmL}^{-1}\right)$ with methanol to have a concentration range of $0.625-10 \mu \mathrm{mL}^{-1}$ for analysis of clopidogrel with atorvastatin and pravastatin; and 1-16 $\mu \mathrm{g} \mathrm{mL}^{-1}$ for simvastatin and rosuvastatin. Sample solutions were prepared to produce same concentration range. The stock solutions of clopidogrel and statins $\left(50 \mu \mathrm{gmL}^{-1}\right)$ were subsequently diluted with buffers to get $25 \mu \mathrm{g} \mathrm{mL}^{-1}$. To have standard solution peaks, $2 \mathrm{~mL}$ of each drug solution prepared in same $\mathrm{pH}$ buffer was mixed, 3 replicates were produced. Sample solutions for clopidogrel and statins were prepared in similar manner. To study these samples at $37^{\circ} \mathrm{C}, 10 \mathrm{~mL}$ of each drug solution prepared in same $\mathrm{pH}$ buffer was mixed and kept on water bath at $37^{\circ} \mathrm{C}$, for 3 hours. The aliquots drawn every 30 minutes were filtered and injected in HPLC using their respective chromatographic conditions.

\section{RESULTS AND DISCUSSION}

\section{Interaction studies by UV spectroscopy}

We investigated the interaction in four different types of media simulating body environments ( $\mathrm{pH} \mathrm{1,} \mathrm{4,} 7.4$ and 9) to investigate the chances of interaction between clopidogrel and statins when they are given concomitantly to atheroma patients. Clopidogrel gives intense spectra with strong hyperchromic and hypsochromic shifts in buffers of $\mathrm{pH} 1$ and 4 (Figure 1) with high molar absorptivity due to its solubility and protonation of nitrogen in acidic medium, while in $\mathrm{pH} 7.4$ and 9 solutions absorptivity is average. In these buffer solutions clopidogrel showed absorption maxima $\left(\lambda_{\text {mav }}\right)$ in the vicinity of $201-203 \mathrm{~nm}$ i.e. very near to cut off region of $U V$, two very small peaks with negligible absorptivity appeared at 270 and $278 \mathrm{~nm}$ as well. Owing to expected errors and solvent absorption occurring at low wavelengths and complete overlapping spectra of interacting drugs that could interfere with direct simultaneous determination, we adopted derivative spectroscopic method based on zero crossing technique to quantify the drugs in mixture. Calibration curves of standard working solutions of clopidogrel and statins were constructed by plotting derivatized absorbance value against concentration at zero-crossing wavelength. The least square regression equations, obtained and their statistical analysis is summarized in Table 1.

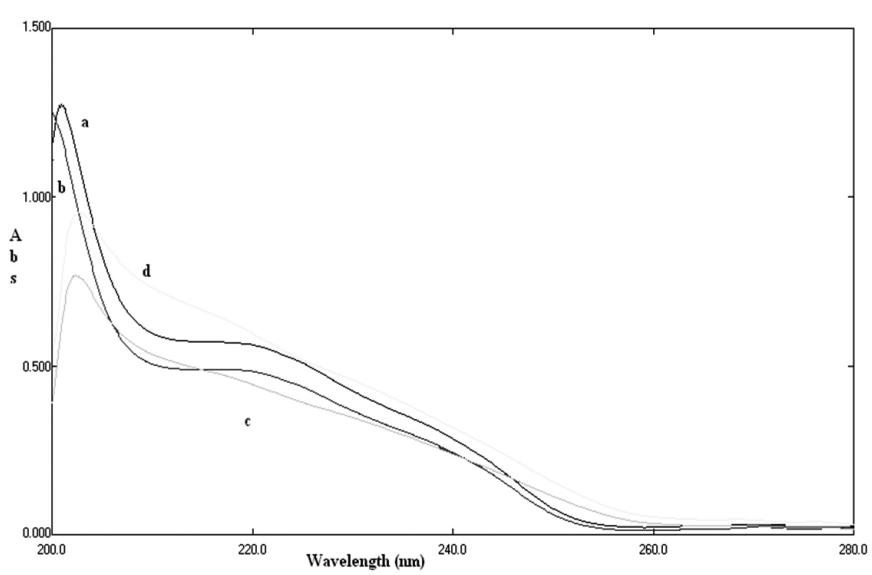

Fig. 1. A comparison of zero-order spectra of $14482 \mu \mathrm{gmL}^{-1}$ clopidogrel in buffers of (a) $\mathrm{pH} 1$ (b) $\mathrm{pH} 4$ (c) $\mathrm{pH} 7.4$ and (d) $\mathrm{pH} 9$.

These studies were carried out to investigate the behavior of drug when taken alone so that we can examine the effect of interacting drug during interaction studies. The concentration of the aliquots was determined by using $y=m x+b$ equation. The percentage of drug availability was calculated for clopidogrel and statins at different time intervals. It was found from data that $112,103,26$ and $23 \%$ drug was available (determined complementary to atorvastatin) in buffers of $\mathrm{pH} 1,4,7.4$ and 9 respectively by the end of experiment. It can be inferred in general that molar absorptivity is decreasing with the increase in $\mathrm{pH}$ of medium.

The different derivative plots of clopidogrel and statins in various interacting medium ( $\mathrm{pH} \mathrm{1,} \mathrm{4,} 7.4$ and 9) are shown in Table 1.

Table 1. Statistical analysis of calibration curves of clopidogrel and statins.

\begin{tabular}{|c|c|c|c|c|c|}
\hline & Der. & & & & \\
\hline \multirow[t]{2}{*}{$\mathrm{pH}$} & order & Regression equation & $\mathrm{R}^{2}$ & Regression equation & $\mathrm{R}^{2}$ \\
\hline & & Clopidogrel & & Atorvastatin & \\
\hline 1.0 & $1^{\text {st }}$ & $\mathrm{y}=-0.324 \mathrm{x}-0.0002$ & 0.9984 & $y=-0.3476 x-0.0002$ & 0.9990 \\
\hline 4.0 & $1 \mathrm{st}$ & $y=-0.3463 x-6 E-05$ & 0.9998 & $y=-1.7121 x+0.0005$ & 0.9851 \\
\hline 7.4 & $1 \mathrm{st}$ & $y=-0.2493 x-0.0014$ & 0.9841 & $y=-0.3853 x+0.0012$ & 0.9997 \\
\hline 9.0 & $1 \mathrm{st}$ & $\mathrm{y}=-0.2931 \mathrm{x}-0.0011$ & 0.9859 & $y=-0.2962 x+3 E-05$ & 0.9993 \\
\hline 4.0 & $1 \mathrm{st}$ & $\mathrm{y}=-0.3115 \mathrm{x}-0.0001$ & 0.9999 & $\mathrm{y}=0.0047 \mathrm{x}-0.0009$ & 0.9965 \\
\hline 7.4 & 2nd & $\mathrm{y}=0.0756 \mathrm{x}+0.0012$ & 0.9323 & $\mathrm{y}=0.0011 \mathrm{x}+1 \mathrm{E}-04$ & 0.9844 \\
\hline \multirow[t]{2}{*}{9.0} & $3 \mathrm{rd}$ & $\mathrm{y}=0.0212 \mathrm{x}-0.0001$ & 0.9422 & $y=-0.0007 x+5 E-05$ & 0.9966 \\
\hline & & Clopidogrel & & Pravastatin & \\
\hline 1.0 & $1 \mathrm{st}$ & $\mathrm{y}=-0.2955 \mathrm{x}-0.0001$ & 0.9964 & $\mathrm{y}=0.5458 \mathrm{x}+0.0006$ & 0.9921 \\
\hline 9.0 & & Clopidogrel & & Rosuvastatin & \\
\hline 1.0 & $1 \mathrm{st}$ & $\mathrm{y}=-0.381 \mathrm{x}-0.0002$ & 0.9982 & $y=-0.5921 x-0.0002$ & 0.9986 \\
\hline 4.0 & $1 \mathrm{st}$ & $\mathrm{y}=-0.3364 x-8 \mathrm{E}-05$ & 0.9999 & $y=-0.6373 x-7 E-06$ & 0.9994 \\
\hline 7.4 & 2nd & $\mathrm{y}=0.0978 \mathrm{x}+0.0017$ & 0.9451 & $y=-0.1423 x-0.0002$ & 0.9851 \\
\hline 9.0 & $1 \mathrm{st}$ & $y=-0.333 x-0.0008$ & 0.9902 & $y=-0.4171 x+3 E-05$ & 0.9997 \\
\hline
\end{tabular}

$1^{\text {st }}$ derivative plot was employed in all $\mathrm{pH}$ to study interaction between clapidogrel atorvastatin. However, in case of sinvastatin and pravastatin, $1^{\text {st }} 2^{\text {nd }}$ and $3^{\text {rd }}$ derivative plots were used to study the interactions spectroscopy in case of pravastatin was applied for $\mathrm{pH} 7.4$ and 9 respectively to achieve maximum resolution. In case of clopidogrel-rosuvastatin interaction, the $1^{\text {st }}$ derivative plot gave non-interfering wavelengths at $\mathrm{pH} 1,4$ and 9 for both the drugs. However, at $\mathrm{pH} 7.4$, 2nd derivative spectroscopy was found appropriate to obtain maximum resolution. The influence of $\Delta \lambda$ was determined to obtain optimum wavelength interval 
by taking into account the noise level, the resolution of the spectrum and the sample concentration. $\Delta \lambda=4 \mathrm{~nm}$ was considered as suitable.

For clopidogrel-atorvastatin interaction at $\mathrm{pH} 1$ the overlain D1 spectra (Figure 2) revealed that clopidogrel had zero amplitude $(\mathrm{D} 1=\mathrm{dA} / \mathrm{d} \lambda=0)$ at $259 \mathrm{~nm}$ where, atorvastatin showed substantial amplitude, atorvastatin showed the same $225 \mathrm{~nm}$. These zero crossing points were utilized for construction of Beer's law plots. The following linear regression equations were obtained and utilized for direct estimation of both drugs in mixture.

$$
\begin{aligned}
& 1 \mathrm{D} 225=-0.324 \mathrm{Cc}-0.0002-\mathrm{-O}(1)\left(\mathrm{R}^{2}=0.9984\right) \\
& 1 \mathrm{D} 259=-0.324 \mathrm{Ca}-0.0002-\mathrm{-o}(2)\left(\mathrm{R}^{2}=0.999\right)
\end{aligned}
$$

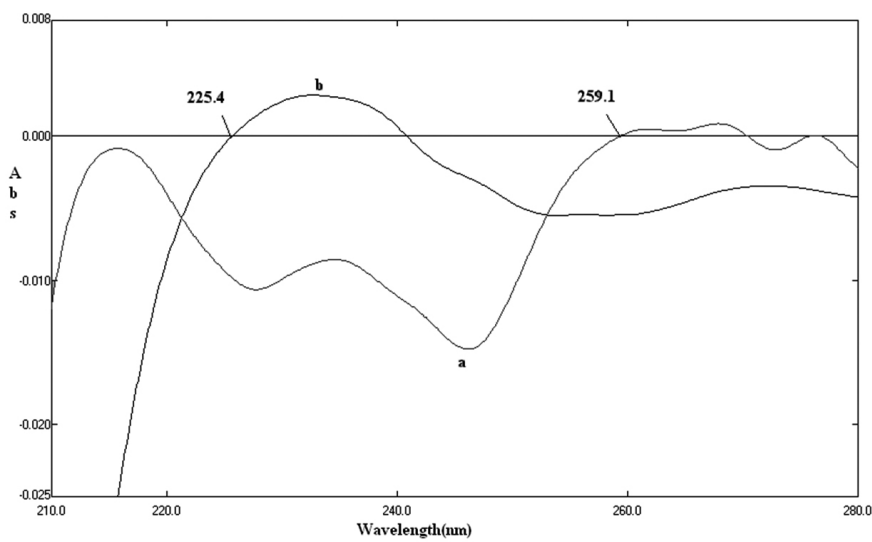

Fig. 2.Overlain 1st derivative spectra of clopidogrel (a) and atorvastatin (b) at simulating gastric $\mathrm{pH}$

The amplitude of derivatized interaction spectra were recorded at selected wavelengths. By employing equation 1 the concentration of both drugs were worked out at $37^{\circ} \mathrm{C}$. Same procedure was repeated for remaining $\mathrm{pH}$, temperature and statins. Results of these interaction studies at both temperatures are plotted in Figures 3-6.

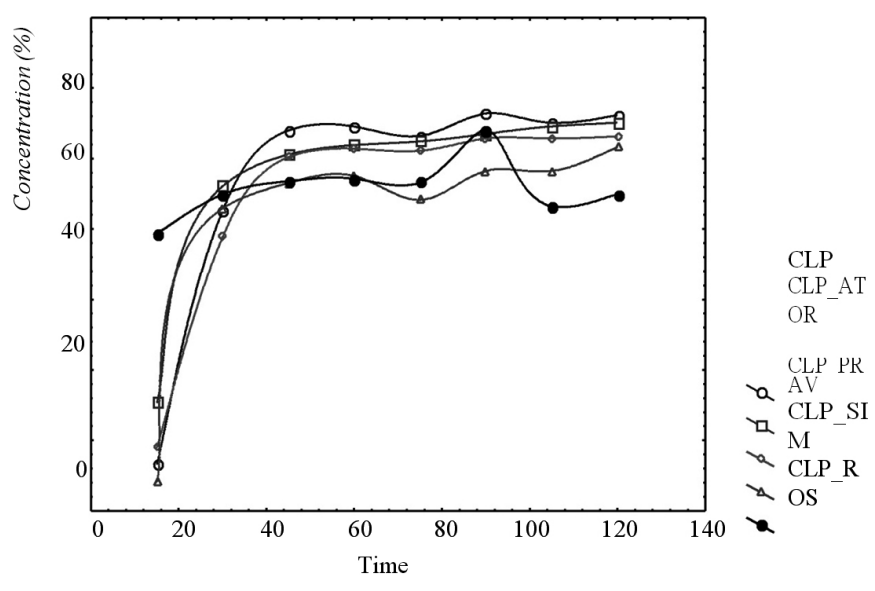

Fig. 3. Concentration of clopidogrel alone and in presence of HMG Co-A reductase inhibitors in simulated gastric juice at $37^{\circ} \mathrm{C}$

The results of interaction study revealed that spontaneous reaction is taking place between clopidogrel and statins. There was no considerable effect on clopidogrel availability at $37^{\circ} \mathrm{C}$ during the reaction with atorvastatin, simvastatin, pravastatin and rosuvastatin at $\mathrm{pH} 1$ when compared to its alone in vitro availability. However, the results showed some random temperature dependent variations in availability of statins in order pravastatin>atorvastat in $>$ simvastatin $>$ rosuvastatin. The outcomes of these changes pointed towards the formation of small or large charge-transfer complex that often gave high availability due to high molar absorptivity, but due to instability broken down during interaction and ended up with reduced availability. At $\mathrm{pH} 4$ results for clopidogrel/atorvastatin interaction showed that

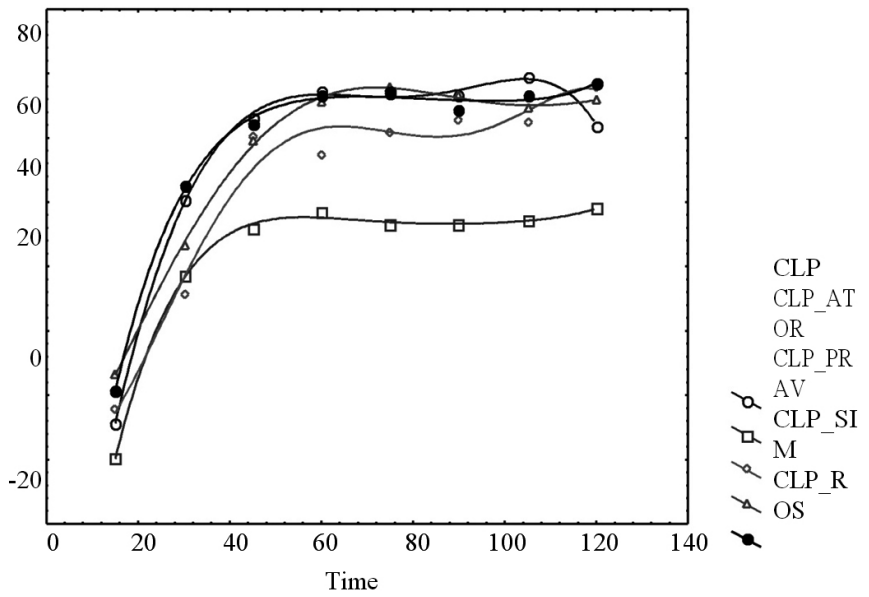

Fig. 4. Concentration of clopidogrel alone and in presence of HMG Co-A reductase inhibitors in buffer of $\mathrm{pH} 4$ at $37^{\circ} \mathrm{C}$

both the drugs effected each other's concentration due to formation of charge-transfer complex in mixture, at $37^{\circ} \mathrm{C}$, the concentration of atorvastatin and clopidogrel were found reduced from 44.0 and $103.8 \%$ (alone availability) to 11 and $78 \%$. The interaction results of clopidogrel with remaining statins exemplified that presence of simvastatin did not affect concentration of clopidogrel significantly in mixture rather it showed large variation on part of statins themselves, again pointing towards the formation of charge-transfer complex. The results of interaction at $\mathrm{pH} 7.4$ showed no significant change in the concentration of clopidogrel and statins, but with rosuvastatin there was a marked decrease in availability of clopidogrel, from $36.4 \%$ (alone availability) to $3.07 \%$. Analysis at $\mathrm{pH} 9$ showed a mix response, presence of atorvastatin resulted in enhanced and pravastatin in reduced concentration of clopidogrel whereas; simvastatin and rosuvastatin couldn't impart any significant effect on concentration of clopidogrel.

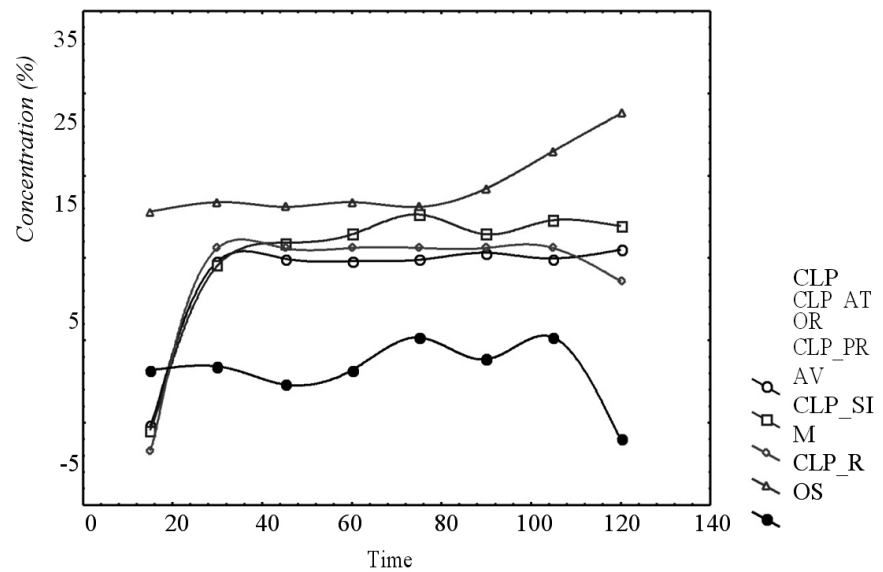

Fig.5. Concentration of clopidogrel alone and in presence of HMG Co-A reductase inhibitors in buffer of $\mathrm{pH} 7.4$ at $37^{\circ} \mathrm{C}$. 


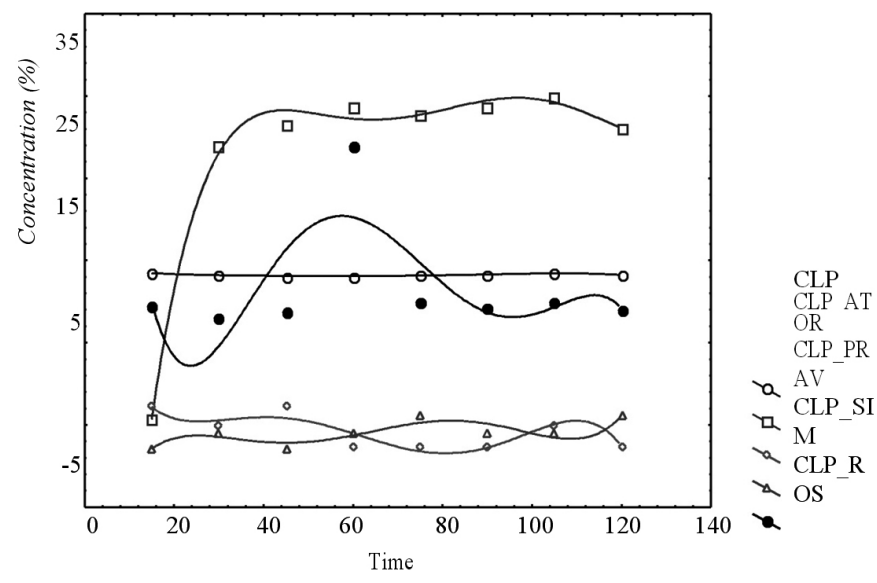

Fig. 6. Concentration of clopidogrel alone and in presence of HMG Co-A reductase inhibitors in buffer of $\mathrm{pH} 9$ at $37^{\circ} \mathrm{C}$.

\section{Interaction studies by RP-HPLC}

To our knowledge no method has been reported for the simultaneous determination of clopidogrel and statins. In present work we report simultaneous quantitation of clopidogrel and statins from bulk materials. Similar analytical and instrumental parameters encouraged developing a combine method for simultaneous analysis of atorvastatin and pravastatin together with clopidogrel and yet achieve sufficient separation. In case of simvastatin and rosuvastatin, methods were developed separately for each as we made some modifications in analytical and instrumental parameters from those used for other two statins, reason being a very long retention time. To optimize the operating conditions for HPLC-UV detection, a systematic investigation was under taken to study effect of parameters such as compositions and $\mathrm{pH}$ of mobile phase and flow rate. Mobile phases with varying compositions of methanol, acetonitrile and water, $\mathrm{pH}$ value $3.5 \pm 0.3$ and flow rate $1 \pm 0.2$ were examined.

The study showed that a $\mathrm{pH}$ value of 3.2 for rosuvastatin and 3.4 for remaining statins; mobile phase composition of methanol: water in ratio of $80: 20(\mathrm{v} / \mathrm{v})$ for atorvastatin and pravastatin, acetonitrile:methanol:water $(60: 30: 10, \mathrm{v} / \mathrm{v} / \mathrm{v})$ for simvastatin and (methanol : water; 65:35 v/v) for clopidogrel- rosuvastatin; flow rate $1.2 \mathrm{~mL} \mathrm{~min}^{-1}$ for rosuvastatin and $1 \mathrm{~mL}$ $\mathrm{min}^{-1}$ for remaining with detection wavelength $240 \mathrm{~nm}$ would be suitable to achieve optimum separation and good detector response. Chromatograms of clopidogrel with atorvastatin-pravastatin, simvastatin and rosuvastatin are shown in Figure 7; all peaks are well resolved. System suitability data for clopidogrel and statins under their respective optimum conditions is shown in Table 2. Linearity of the analytical method was evaluated using pharmaceutical standards in the range of $0.625-10 \mu \mathrm{g} \mathrm{mL}^{-1}$ for atorvastatinpravastatin and $1-16 \mu \mathrm{g} \mathrm{mL}^{-1}$ simvastatin and rosuvastatin with clopidogrel for three consecutive Calibration curves were constructed and linear relationship was obtained between the peak area and the corresponding concentration with correlation coefficients greater than 0.9998 (Table 3).

Table 2. System-suitability data for separation of clopidogrel and statins under optimum separation conditions.

\begin{tabular}{|c|c|c|c|c|c|}
\hline Drugs & $\mathrm{Rt}$ & $\mathrm{k}$ & $\mathrm{A}_{\mathrm{S}}$ & $\mathrm{N}$ & $\mathrm{R}_{\mathrm{S}}$ \\
\hline Clopidogrel & 4.4 & 1.51 & 1.36 & 6092 & 2.9 \\
\hline Atorvastatin & 5.2 & 1.99 & 1.31 & 3813 & 2.94 \\
\hline Pravastatin & 3.7 & 1.12 & 2.06 & 3391 & 4.08 \\
\hline Simvastatin & 6.2 & 2.49 & 1.19 & 7420 & 2.93 \\
\hline Rosuvastatin & 6.6 & 2.26 & 2.42 & 3618 & 7.74 \\
\hline
\end{tabular}

$\mathrm{Rt}=$ retention time, $\mathrm{K}=$ capacity factor; $\mathrm{A}_{\mathrm{S}}=$ peak asymmetry; $\mathrm{N}=$ number of theoretical plates; $\mathrm{R}_{\mathrm{S}}=$ resolution

The accuracy of the method was evaluated by calculating the recovery of these drugs by spiking known amount of drugs at three different levels of the calibration range. The percent recoveries were found in the range of 96.65 $100.5,102.90-102.95,101.85-106.11 \%$ and coefficient of variation for intraday and inter-day were found to be in the range of $11.85-12.82 \%, 3.21-8.71 \%$ and $4.55-5.53 \%$ for clopidogrel, atorvastatin and pravastatin respectively. In case of clopidogrel-simvastatin, the coefficient of variation were found to be in the range of $13.11-14.66 \%$ and $8.33-8.46 \%$, and the percent recovery was $94.7-110.2 \%$ and $103.9-109.12 \%$ for clopidogrel and simvastatin respectively indicating that the method is sufficiently accurate. Third validating process involving clopidogrel-rosuvastatin gave percent recovery in the range of $101.9-102.4 \%$ for clopidogrel and $99.0-102.0 \%$ and coefficients of variation $2.37-5.39 \%$ and $1.31-1.83 \%$ for clopidogrel and rosuvastatin respectively.

The limits of detection were found to be $0.766 \mu \mathrm{g} \mathrm{mL}^{-1}, 0.144 \mu \mathrm{g} \mathrm{mL}^{-1}$ and $0.093 \mu \mathrm{g} \mathrm{mL}-1$ while limits of quantification were $2.32 \mu \mathrm{g} \mathrm{mL}^{-1}, 0.436 \mu \mathrm{g} \mathrm{mL}^{-1}$ and $0.282 \mu \mathrm{gmL}^{-1}$ for clopidogrel, atorvastatin and pravastatin respectively. For clopidogrel- simvastatin validation process limits of detection were 1.57 $\mu \mathrm{g} \mathrm{mL}{ }^{-1}, 0.019 \mu \mathrm{gmL}^{-1}$ and limits of quantification were $4.75 \mu \mathrm{g} \mathrm{mL}^{-1}$ and $0.058 \mu \mathrm{g} \mathrm{mL}{ }^{-1}$ for clopidogrel and simvastatin respectively. And finally limits of detection were found to be $0.097 \mu \mathrm{g} \mathrm{mL}^{-1}$ and $0.056 \mu \mathrm{gmL}^{-1}$ and the limits of quantification were $0.294 \mu \mathrm{g} \mathrm{mL}-1$ and $0.168 \mu \mathrm{g} \mathrm{mL}^{-1}$ for clopidogrel and rosuvastatin respectively.

Table 3. Linearity data, accuracy and precision of clopidogrel and statins

\begin{tabular}{|c|c|c|c|c|c|}
\hline Parameters & Clopidogrel & Atorvastatin & Pravastatin & Simvastatin & Rosuvastatin \\
\hline Linearity $(\mu \mathrm{g} / \mathrm{mL})$ & $0.625-10$ & $0.625-10$ & $0.625-10$ & $1-16$ & $1-16$ \\
\hline Regression Equation $\mathrm{y}=$ & $4596.6 \mathrm{x}+717.52$ & $13473 \mathrm{x}-2484.4$ & $9579.2 \mathrm{x}+981.06$ & $13598 \mathrm{x}-8799.6$ & $7597.2 \mathrm{x}+423.44$ \\
\hline $\mathrm{r}^{2}$ & 0.9998 & 0.9979 & 0.9991 & 0.998 & 0.9999 \\
\hline LOD $(\mu \mathrm{g} / \mathrm{mL})$ & 0.766 & 0.144 & 0.093 & 0.019 & 0.058 \\
\hline LOQ $(\mu \mathrm{g} / \mathrm{mL})$ & 2.32 & 0.436 & 0.282 & $103.9-109.12$ & 9.168 \\
\hline Accuracy $(\%)$ & $96.65-100.50$ & $102.90-102.95$ & $101.85-106.11$ & - & - \\
\hline Precision $(\% \mathrm{RSD}$ & - & - & - & 8.33 & 5.39 \\
\hline Intra-day $(\mathrm{n}=3)$ & 11.853 & 3.214 & 4.554 & 5.46 & \\
\hline Inter-day $(\mathrm{n}=3)$ & 12.826 & 8.719 & 5.533 & & 1.311 \\
\hline
\end{tabular}

To determine the robustness of the method, experimental conditions like mobile phase ratio, $\mathrm{pH}$ of the mobile phase were altered slightly. Mobile phase of methanol and water with 80:20 combination and $\mathrm{pH} 3.4$ was found suitable for simultaneous determination of these drugs.

The ruggedness of the method was determined by performing the same assay by different analysts and performing the assay on different days to check the reproducibility. The results were found to be highly reproducible. The system suitability parameters for the proposed method were calculated. All peaks were symmetrical. Various validation parameters for the proposed LC method are summarized in Table 3.

At $\mathrm{pH} 1$ the area under curve (AUC) and availabilities obtained for clopidogrel and atorvastatin after $30 \mathrm{~min}$ were $75 \%$ and $47 \%$ that went up to $145 \%$ and $72 \%$ by the end. This confirmed clopidogrel suppressing atorvastatin, in turn its own concentration was enhanced to almost double. At $\mathrm{pH} 4$ and 9 , both drugs were interacting to reach a final availability of $140 \%, 123 \%$ (clopidogrel) and $127 \%, 145 \%$ (atorvastatin). No interaction was found in buffer of $\mathrm{pH}$ 7.4. Results of interaction with statins are mentioned in Table 4. As the case with atorvastatin, here also presence of clopidogrel 
suppressed availability of pravastatin that declined at $\mathrm{pH} 1$ from 104-17\% by the end of experiment. At $\mathrm{pH} 4$, interaction occurred at clopidogrel side whose concentration dropped from 120 to $112 \%$. At $\mathrm{pH} 7.4$, enhanced concentrations of both drugs were obtained and reverse was true in case of $\mathrm{pH} 9$ buffer.

The interaction has occurred between these drugs at all $\mathrm{pH}$. At $\mathrm{pH} \mathrm{1,}$ availability of clopidogrel reached to $124 \%$ from $104 \%$, while the drug that gave the evidence of strong interaction was simvastatin that declined from 51 to $15.9 \%$ by the end. There seem to be no interaction at $\mathrm{pH} 4$ with 120 and $111 \%$ achieved for clopidogrel and simvastatin respectively. $\mathrm{pH} 7.4$ and 9 favored more interaction on clopidogrel side where concentration remained 66 and 44\% respectively after 3 hours. In case of rosuvastatin, availability of clopidogrel was increased in simulated gastric juice $(\mathrm{pH} 1)$ and $\mathrm{pH} 4$ while in buffers of $\mathrm{pH} 7.4$ and 9 availability of rosuvastatin was increased upto $179 \%$. (Table 4).

At $\mathrm{pH} 1$, rosuvastatin reacted and enhanced the concentration of clopidogrel gradually from 103 to $185 \%$ over a period of 3 hours. $\mathrm{pH} 4$ favored interaction for the drugs, their concentrations increased in range of $126-206 \%$ for clopidogrel and $123-186 \%$ for rosuvastatin. The results obtained at $\mathrm{pH}$ 7.4 and 9 were catching attraction more on the side of rosuvastatin where concentration was enhancing to $117-179 \%$ and $114-161 \%$ while causing the concentration of clopidogrel to drop from $100-99 \%$ and $120-110 \%$ at $\mathrm{pH} 7.4$ and 9 respectively (Table 4).

Table 4. \% Availability of clopidogrel and statins interaction monitoring by HPLC.

\begin{tabular}{|c|c|c|c|c|c|c|c|c|}
\hline Time (min) & Clop $^{1}$ & Ator $^{2}$ & Clop $^{1}$ & $\operatorname{Prav}^{3}$ & Clop $^{1}$ & $\mathrm{Sim}^{4}$ & Clop1 & Ros. $^{5}$ \\
\hline & & & & pH 1 & & & & \\
\hline 30 & 75.68 & 47.66 & 104.15 & 104.38 & 104.35 & 51.07 & 103.36 & 107.26 \\
\hline 60 & 101.61 & 61.55 & 111.99 & 34.72 & 138.95 & 43.89 & 116.69 & 110.58 \\
\hline 90 & 106.37 & 62.89 & 119.58 & 24.69 & 122.21 & 40.86 & 127.76 & 114.24 \\
\hline 120 & 110.51 & 62.36 & 117.37 & 20.51 & 141.32 & 37.09 & 129.86 & 112.2 \\
\hline 150 & 129.81 & 69.86 & 109.78 & 102.1 & 13.4 & 36.63 & 160.9 & 131.31 \\
\hline \multirow[t]{2}{*}{180} & 145.12 & 72.57 & 95.87 & 17.03 & 124.41 & 15.93 & 185.52 & 122.49 \\
\hline & & & & $\mathrm{pH} 4$ & & & & \\
\hline 30 & 107.73 & 100.96 & 120.43 & 94.54 & 106.99 & 72.25 & 126.94 & 123.65 \\
\hline 60 & 102.82 & 102.86 & 125.56 & 95.85 & 104.52 & 94.04 & 128.39 & 126.37 \\
\hline 90 & 108 & 111.83 & 126.55 & 94.46 & 101.51 & 96.66 & 134.71 & 133.56 \\
\hline 120 & 95.48 & 99.7 & 113.46 & 85.16 & 53.32 & 102.19 & 141.8 & 143.34 \\
\hline 150 & 117.78 & 118.18 & 116.48 & 96.42 & 110.37 & 100.15 & 167.28 & 164.89 \\
\hline \multirow[t]{2}{*}{180} & 140.4 & 127.38 & 112.47 & 101.07 & 120.05 & 111.34 & 206.73 & 186.82 \\
\hline & & & & $\mathrm{pH} 7.4$ & & & & \\
\hline 30 & 133.25 & 98.17 & 136.27 & 135.74 & 51.35 & 94.33 & 100.1 & 117.63 \\
\hline 60 & 128.2 & 75.17 & 224.36 & 179.14 & 73.07 & 103.94 & 111.46 & 118.72 \\
\hline 90 & 140.59 & 78.71 & 161.9 & 159.6 & 39.98 & 104.53 & 131.05 & 126.03 \\
\hline 120 & 144.13 & 80.35 & 155.02 & 161.42 & 76.85 & 101.84 & 121.95 & 137.11 \\
\hline 150 & 162.11 & 94 & 156.03 & 161.36 & 66.95 & 99.69 & 127.82 & 149.57 \\
\hline \multirow[t]{2}{*}{180} & 114.42 & 102.37 & 156.69 & 177.1 & 66.65 & 89.75 & 99 & 179.97 \\
\hline & & & & pH 9 & & & & \\
\hline 30 & 104.76 & 93.3 & 145.46 & 159.4 & 65.69 & 95.37 & 120.17 & 114.64 \\
\hline 60 & 110.95 & 99.99 & 148.98 & 150.92 & 63.45 & 97.33 & 111.48 & 62.88 \\
\hline 120 & 115.43 & 115.67 & 139 & 138.4 & 21.61 & 106.67 & 127.45 & 127.4 \\
\hline 150 & 120.41 & 124.02 & 130.39 & 130.85 & 80 & 110.06 & 134.82 & 143.46 \\
\hline 180 & 123.9 & 145.11 & 129.76 & 128.65 & 44.27 & 114.4 & 110.69 & 161.65 \\
\hline
\end{tabular}

\section{CONCLUSION}

In conclusion, the present work includes drug interaction studies between clopidogrel bisulfate and HMG Co-A reductase inhibitors (atorvastatin, pravastatin, simvastatin, rosuvastatin) via UV/VIS spectrophotometer and RP-LC. The results obtained assisted to deduce that the presence of these drugs together interfere with each other's \% availability due to charge transfer complex formation. On the basis of above mentioned studies it has been anticipated that co-administration of clopidogrel bisulfate with HMG Co-A reductase inhibitors forms charge-transfer complexes that may alter the availability and thus the therapeutic activity of statins. 

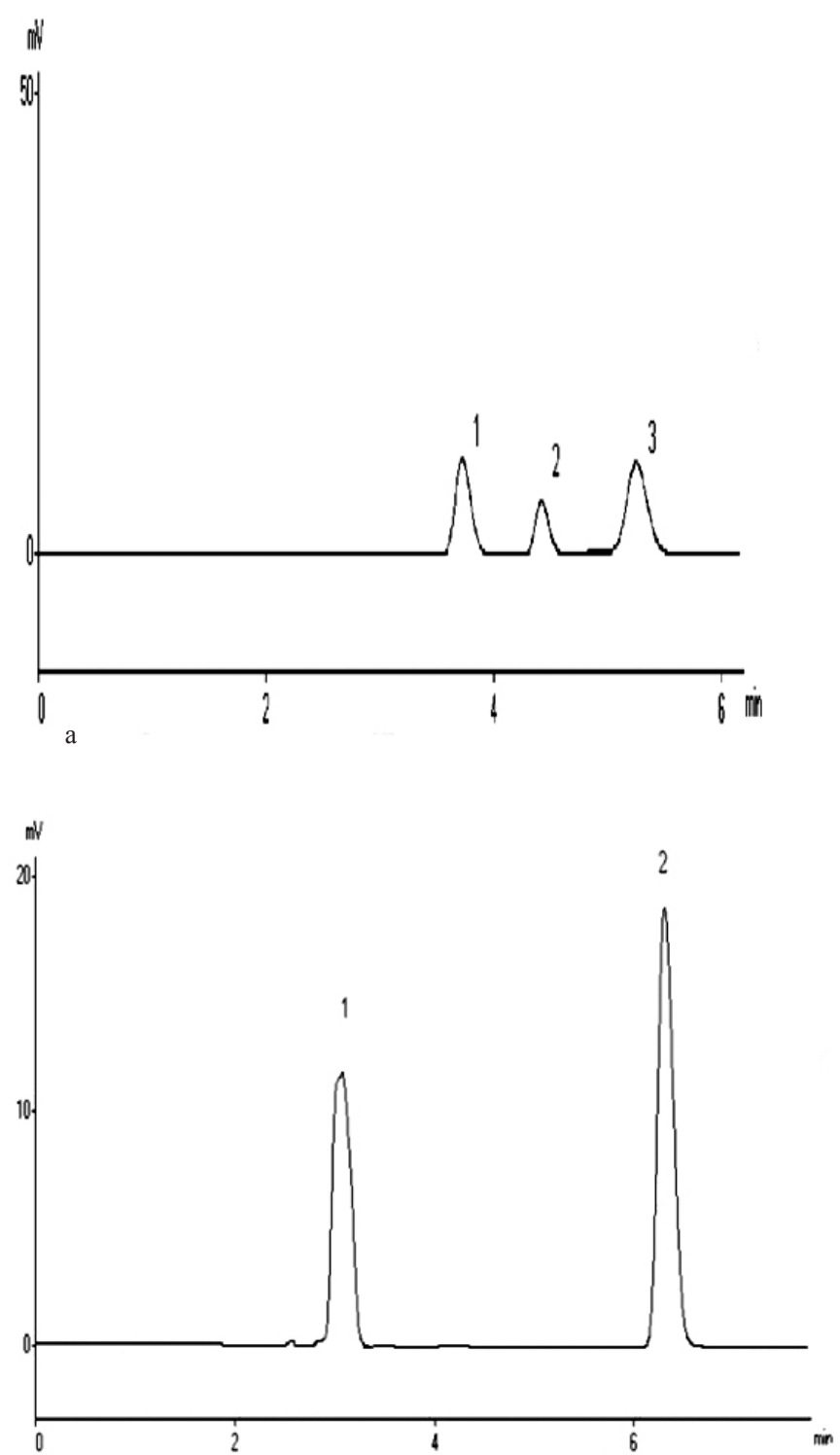

$\mathrm{b}$

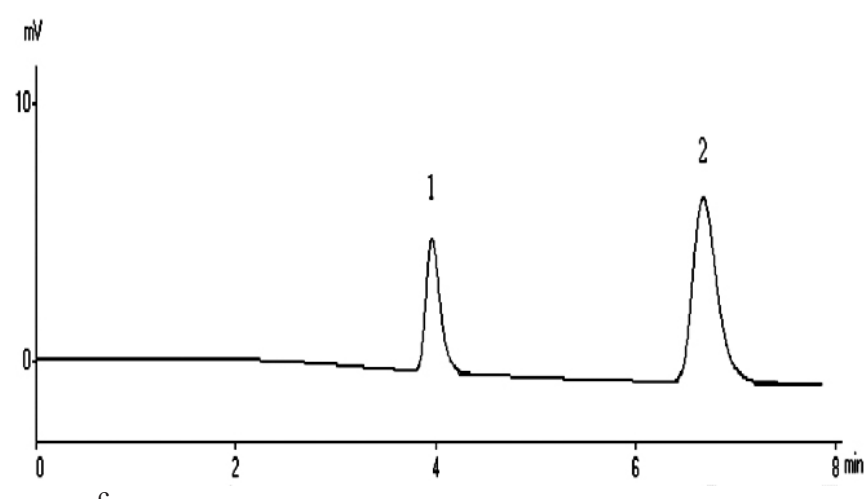

Fig. 7. Chromatograms of pravastatin ${ }^{1}$, clopidogrel $^{2}$ and atorvastatin ${ }^{3}($ a) clopidogrel ${ }^{1}$ and simvastatin ${ }^{2}$ (b) clopidogrel ${ }^{1}$ and rosuvastatin ${ }^{2}(\mathbf{c})$

\section{REFERENCES}

1 J.M. Herbert, D. Frehel, A. Bernat, A. Badorc, P. Savi, D. Delebassée, G. Kieffer G. Defreyn, J.P. Maffrand, Drug Future, 18, 107, (1993).

2 P. Savi, J. Combalbert, C. Gaich, M.C. Rouchon, J.P. Maffrand, Y. Berger, J.M. Herbert, Thromb Haemostasis 72, 313, (1994).

3 M.H. Moghadasian, Life Sci. 65, 1329, (1999).

4 J. Davignon, M. Montigny, R. Dufour, Can. J. Cardiol. 8, 843, (1992).

5 H.T. Mabuchi, Y. Sakai, A. Sakai, A. Yoshimura, T. Watanebe, J. Wakasugi, J. Koizumi, R. Takeda, New Engl. J.Med. 308, 609, (1983).

6 H. Mabuchi, T. Haba, R. Tatami, S. Miyamoto, Y. Sakai, T. Wakasugi, A. Watanebe, J. Koizumi, R. Takeda, New Engl. J. Med. 305, 478, (1981).

7 D.W. Bilheimer, S.M. Grundy, M. S. Brown, J. L. Goldstein, Proc. Natl. Acad. Sci. 80, 4124, (1983).

8 Y. Arad, R. Ramakrishnan, H.N. Ginsberg, Metabolism 41, 487, (1992).

9 V.L. Serebruany, M.G. Midei, A.I. Malinin, B.R. Oshrine, D.R. Lowry, D.C. Sane, J.F. Tanguay, S.R. Steinhubl, P.B. Berger, C.M. O'Connor, C.H. Hennekens, Arch. Intern. Med. 164, 2051, (2004).

10 I. Muller, F. Besta, C. Li. Z. Schulz, S. Massberg, M. Gawaz, Circulation, 108, 2195, (2003).

11 J. V. Mitsios, A. I. Papathanasiou, F. I. Rodis, M. Elisaf, J. A. Goudevenos, A.D.Tselepis, Circulation, 109, 1335, (2004).

12 S.M. Smith, H.M. Judge, G. Peters, R.F. Storey, Platelets 15, 465, (2004).

13 J. Karpinska, M. J. Mulikowska, Pharm. Biomed. Anal. 29, 153, (2002).

14 B. J. Morelli, Pharm. Sci. 84, 34, (1995). 